\title{
Sildenafil Citrate (Viagra) Induces Cardioprotective Effects after Ischemia/Reperfusion Injury in Infant Rabbits
}

\author{
YVONNE A. BREMER, FADI SALLOUM, RAMZI OCKAILI, ERIC CHOU, \\ WILLIAM B. MOSKOWITZ, AND RAKESH C. KUKREJA \\ Division of Pediatric Cardiology, Department of Pediatrics [Y.A.B., W.B.M.], Division of Cardiology, \\ Department of Medicine [F.S., R.O., E.C., R.C.K.], Virginia Commonwealth University Health System, \\ Richmond, Virginia, 23298
}

\begin{abstract}
Infants undergoing surgery for congenital heart disease are at risk for myocardial ischemia during cardiopulmonary bypass, circulatory arrest, or low-flow states. The purpose of this study was to demonstrate the effects of sildenafil, a selective phosphodiesterase-5 (PDE-5) inhibitor on myocardial functional improvement and infarct size reduction during ischemia/reperfusion injury in infant rabbits. Infant rabbits (aged $8 \mathrm{wk}$ ) were treated with sildenafil citrate $(0.7 \mathrm{mg} / \mathrm{kg}$ i.v. $)$ or normal saline $30 \mathrm{~min}$ before sustained ischemia for $30 \mathrm{~min}$ and reperfusion for $3 \mathrm{~h}$. Transesophageal echocardiography (TEE) was used to assess left ventricular cardiac output (LVCO) and aortic velocity time integral (VTI). After ischemia/reperfusion, risk area was demarcated by Evan's blue dye and infarct size determined by computer morphometry of triphenyltetrazolium chloride-stained sections. The sildenafil-treated group had preservation and elevation in LVCO $(143 \%$ of baseline, $p<0.05)$ and an elevated aortic VTI $(145 \%$ of baseline, $p<0.05)$ after $30 \mathrm{~min}$ of ischemia compared with the control group LVCO (72\% of baseline, $p<$ $0.05)$ and aortic VTI (73\% of baseline, $p<0.05)$. This is a statistically significant increase in LVCO and aortic VTI in the sildenafil group compared with controls $(n=6$ /group, $p<0.05$ ).
\end{abstract}

ABSTRACT

The sildenafil-treated group had significant reduction in infarct size $(15.5 \pm 1.2$ versus $33 \pm 2.3$ in the saline group, \% risk area, mean \pm SEM, $n=10-15$ /group, $p<0.05$ ). For the first time, we have shown that sildenafil citrate promotes myocardial protection in infant rabbits as evidenced by postischemic preservation and elevation in LVCO and aortic VTI and reduction in infarct size.

(Pediatr Res 57: 22-27, 2005)
HR, heart rate
Abbreviations
LAD, left anterior descending
$\mathbf{L V}$, left ventricle
LVCO, left ventricular cardiac output
LVOT, left ventricular outflow tract
MAP, mean arterial pressure
PDE-5, phosphodiesterase-5
SVR, systemic vascular resistance
TEE, transesophageal echocardiography
TTC, 2,3,5-triphenyltetrazolium chloride
VTI, velocity time integral

Each year, more than 25,000 children undergo corrective surgery for congenital heart disease. Early surgical intervention is important to promote more normal development. Infants undergoing surgery for congenital heart disease are at risk for myocardial ischemia during cardiopulmonary bypass, circulatory arrest, or low-flow states (1). Less is known about the tolerance of the infant myocardium to ischemia compared with the adult, and cardiac reserves are more limited in the infant

Received March 22, 2004; accepted July 12, 2004.

Correspondence: Rakesh C. Kukreja, Ph.D., Professor of Medicine, Box 281, Division of Cardiology, Medical College of Virginia, VA Commonwealth University, Richmond, VA 23298; e-mail: rakesh@hsc.vcu.edu

Supported, in part, by Grants HL 51045 and HL-59469 from the National Institutes of Health (R.C.K.).

DOI: 10.1203/01.PDR.0000147736.27672.15
(2). Although there is evidence that the infant myocardium may be more resilient to metabolic or ischemic injury compared with adults, the infant heart responds quite differently to cardiovascular drugs, stress, and changes in hemodynamics $(3,4)$. Although hypothermia combined with pharmacologic cardioplegia protects the globally ischemic adult heart, this benefit may not extend to infants. For example, poor postischemic recovery of function and increased mortality may result when this method of myocardial protection is used in children (5). Therefore, there is a need to develop novel pharmacological approaches to protect infant hearts from ischemia/ reperfusion injury.

Brief episodes of ischemia protect the myocardium from more prolonged periods of ischemia, a phenomenon called ischemic preconditioning (6). A variety of other stimuli, such 
as hypoxia, thermal stress, pharmacologic agents, and endogenous triggers of preconditioning such as nitric oxide and adenosine have also been shown to induce cardioprotective effects in several animal species (7-10). Also, recent studies from our laboratory have shown that sildenafil citrate (Viagra), a selective PDE-5 inhibitor, induces powerful preconditioninglike protective effects in the ischemic heart (11). However, it is not known whether sildenafil exerts similar protective effects against ischemia/reperfusion injury in the infant rabbit hearts as well. The purpose of this study was a) to show whether pretreatment of infant rabbits with clinically relevant dose of sildenafil improves postischemic myocardial function and b) to demonstrate whether this drug reduces myocardial infarct size after ischemia/reperfusion. We used the model of coronary artery occlusion and reperfusion in infant rabbits, which is similar to our previously described adult rabbit model of myocardial infarction (11). This model may be applicable in pediatrics, and especially in pediatric cardiovascular surgery where there may be periods of ischemia/reperfusion injury. Also, for the first time, we used two-dimensional (2D) and Doppler TEE for the estimation of LVCO and aortic VTI in this model.

\section{METHODS}

Animals. Eight-week-old male New Zealand White rabbits with mean weight of $2.0 \mathrm{~kg}$ (range, $1.3-2.6 \mathrm{~kg}$ ) were used for the study. The care and use of the animals were conducted in accordance with the guidelines of the Institutional Animal Care and Use Committee of Virginia Commonwealth University and the National Institutes of Health Guide for the Care and Use of Laboratory Animals [DHHS Publication No. (NIH) 80-23; Office of Science and Health Reports, Bethesda, MD 20205]. We chose 8-wk-old rabbits because they are similar in size to human neonates or young infants who undergo surgery for congenital heart disease early on in life. We believe this model to be different from the adult rabbit model as well as helpful and similar to young human infants because of similar size, presence of thymic tissue (and thus not having had undergone significant stress yet), and being prepubertal. We thus believe that the physiology and responses to stress and ischemia may be similar to that of human infants.

Study protocol. The rabbits were anesthetized using intramuscular injection of ketamine $\mathrm{HCl}(35 \mathrm{mg} / \mathrm{kg})$ and xylazine $(5 \mathrm{mg} / \mathrm{kg})$. Subsequent doses of ketamine and xylazine at $10 \mathrm{mg} / \mathrm{kg}$ and $2 \mathrm{mg} / \mathrm{kg}$, respectively, were given at 40-min intervals to maintain surgical anesthesia. Atropine was administered along with the anesthetic to prevent reflex bradycardia. Direct tracheotomy and intubation using an uncuffed 2.5 ETT was performed via ventral midline incision in the neck. The rabbits were mechanically ventilated with tidal volumes of $\sim 8 \mathrm{~mL} / \mathrm{kg}$ and rates of $25-35$ breaths per minute while arterial blood gases were monitored to maintain physiologic $\mathrm{pH}$ and $\mathrm{O}_{2}$ saturation $>90 \%$. The internal jugular vein was cannulated and $0.9 \%$ normal saline was infused at $50 \mathrm{~mL} / \mathrm{h}$ throughout the experiment, and the carotid artery was cannulated for continuous monitoring of hemodynamics and arterial blood gases. Continuous ECG was performed to confirm normal ST segments at baseline and ST segment elevation during the ischemic period. Temperature was monitored throughout the experiment and maintained at $37^{\circ} \mathrm{C}$. The injectable solution of sildenafil was prepared directly by crushing $50 \mathrm{mg}$ tablets of sildenafil, determining the $0.7 \mathrm{mg} / \mathrm{kg}$ amount, and dissolving this in $3 \mathrm{~mL}$ of normal saline. The control group received $3 \mathrm{~mL}$ of normal saline alone. The inactive ingredients in the sildenafil tablets consist of microcrystalline cellulose, anhydrous dibasic calcium phosphate, croscarmellose sodium, magnesium stearate, hydroxypropyl methylcellulose, titanium dioxide, lactose, triacetin, and FD \& C Blue \#2 aluminum lake. This preparation, approximating on a milligram per kilogram basis the clinical dose of $50 \mathrm{mg}$ administered to a $70 \mathrm{~kg}$ patient as reported previously (11), or $0.9 \%$ normal saline for controls was given as an intravenous bolus through the internal jugular catheter $30 \mathrm{~min}$ before ischemia. Left thoracotomy was performed through the fourth intercos- tal space, and the pericardium was excised to expose the heart. A 5-0 silk suture was passed around the LAD coronary artery midway between the atrioventricular groove and apex of the heart. The ends of the suture were threaded through a vinyl tube to create a snare for the period of ischemia. Sustained ischemia for $30 \mathrm{~min}$ was induced by tightening the snare with a hemostat, followed by reperfusion for $3 \mathrm{~h}$.

\section{TEE}

TEE, using a 10-Fr AcuNav diagnostic ultrasound probe (Acuson Corp., Siemens, Iselin, NJ), inserted into the esophagus, was performed at baseline, after the $30 \mathrm{~min}$ period of ischemia, and after $3 \mathrm{~h}$ of reperfusion in both the control and sildenafil groups. Standardized 2D imaging in a long axis view of the LV to show LV inflow across the mitral valve and LVOT was obtained (Fig. 1) (12). Aortic flow Doppler across the aortic valve was performed in a long axis view of the LV and LVOT to obtain LVCO (Fig. 2). The standard equation: mean velocity $(\mathrm{cm} / \mathrm{s}) \times$ flow area $\left(\mathrm{cm}^{2}\right) \times 60(\mathrm{~s} / \mathrm{min})$, where mean velocity $(\mathrm{cm} / \mathrm{s})=\operatorname{VTI}($ in $\mathrm{cm} /$ beat $) \div \mathrm{RR}$ interval (s/beat), was used to obtain LVCO, expressed in milliliters per minute $(12,13)$. Laminar Doppler flow across the aortic valve confirmed the absence of aortic stenosis. Color Doppler assessment was made of both the aortic and mitral valves again in the long axis view at baseline, after the ischemic period, and after $3 \mathrm{~h}$ of reperfusion for the presence or absence of mitral or aortic regurgitation. Subjective functional assessment was also made after ischemia and reperfusion to demonstrate at least left ventricular apical diminished contractility to confirm infarction.

\section{MEASUREMENT OF INFARCT SIZE}

After the $3 \mathrm{~h}$ reperfusion period, the heart was removed and mounted on a Langendorff apparatus. The coronary arteries were perfused with a $0.9 \%$ normal saline solution containing $2.5 \mathrm{mM} \mathrm{CaCl}_{2}$. The LAD was ligated using the existing suture, and $2 \mathrm{~mL}$ of $10 \%$ Evan's blue dye was injected into the aorta. The heart was then perfused with the saline solution again to wash out the excess dye. The hearts were then removed from the Langendorff apparatus and frozen. Four to six frozen

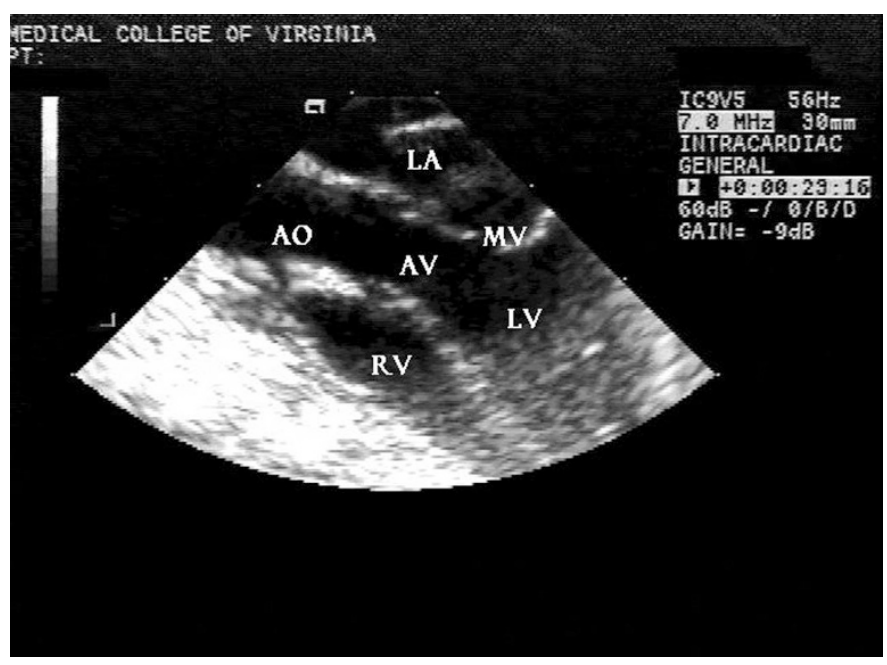

Figure 1. Still-frame 2D TEE of LVOT. $L A$, left atrium; $M V$, mitral valve; $L V$, left ventricle; $A V$, aortic valve; $A O$, aorta; $R V$, right ventricle. 


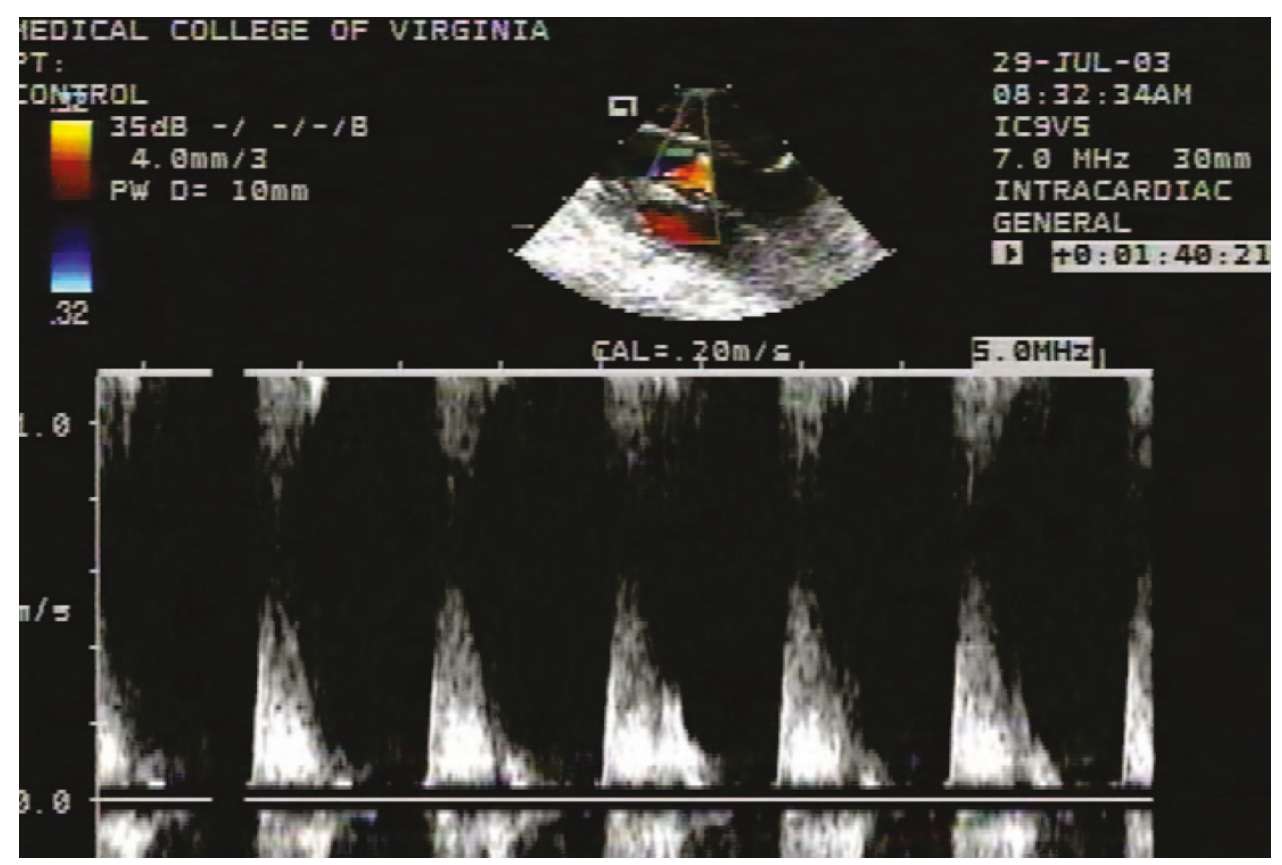

Figure 2. Still-frame Doppler across aortic valve, velocity $v s$ time

sections of the LV from apex to base were taken at $\sim 1-\mathrm{mm}$ thicknesses. The slices were incubated in $1 \%$ TTC solution in isotonic $\mathrm{pH} 7.4$ phosphate buffer at $37^{\circ} \mathrm{C}$ for $20 \mathrm{~min}$. TTC reacts with $\mathrm{NADH}$ in the presence of dehydrogenase enzymes so that viable cells stain red. The myocardium at risk was determined by negative staining with Evan's blue, and the infarcted myocardium was gray-white. Computer morphometry was used to calculate the left ventricular area, risk area, and infarct. Infarct size was then expressed as a percentage of the risk area. Left ventricular cavity and papillary muscle area were excluded.

\section{STATISTICAL ANALYSIS}

All measurements of LVCO, aortic VTI, infarct size, and risk areas are expressed as group means \pm SEM. Changes in hemodynamics, LVCO, aortic VTI, and infarct size variables were analyzed by one-way repeated-measures ANOVA. If the global tests showed major interactions, post hoc contrasts between different groups were performed using $t$ test. Statistical differences were considered significant if the $p$ value was $<0.05$.

\section{RESULTS}

Animals and exclusion. A total of 34 rabbits were used in the study; 20 in the sildenafil group and 14 in the control group. Two rabbits in the control group died before completion of the 3-h reperfusion period due to hypotension, arrhythmias, and acidosis. TEE was performed on 12 rabbits; 6 in the sildenafil group and 6 in the control group. Two rabbits in the control group did not undergo TEE after $3 \mathrm{~h}$ of reperfusion due to technical difficulties with the TEE machine. A total of 25 rabbit hearts were examined for infarct size, 15 in the sildenafil group and 10 in the control group. The nine rabbit hearts that did not stain well were excluded from the study.

Hemodynamics. Changes in hemodynamics are summarized in Table 1. The rabbits treated with sildenafil had a $34 \%$ decline in MAP and an $8 \%$ increase in HR after drug administration compared with the controls $(p<0.05)$. However, MAP and HR were comparable in both groups before the ischemic period. After $30 \mathrm{~min}$ ischemia, MAP and HR were also comparable in both the groups, although a significant decline in MAP compared with the baseline values was ob-

Table 1. Hemodynamic data during ischemia/reperfusion

\begin{tabular}{|c|c|c|c|c|c|c|c|}
\hline & \multirow[b]{2}{*}{ Baseline } & \multirow{2}{*}{$\begin{array}{c}\text { After } \\
\text { saline/drug }\end{array}$} & \multirow[b]{2}{*}{ Preischemia } & \multirow{2}{*}{$\begin{array}{c}\text { End } \\
\text { ischemia }\end{array}$} & \multicolumn{3}{|c|}{ Reperfusion time (h) } \\
\hline & & & & & 1 & 2 & 3 \\
\hline \multicolumn{8}{|l|}{ Controls } \\
\hline MAP & $85.4 \pm 3.7$ & $84.3 \pm 3.4$ & $80.5 \pm 3.8$ & $73.1 \pm 4.3 \S$ & $75.1 \pm 3.4$ & $75.3 \pm 3.4$ & $69.7 \pm 3.5 \S$ \\
\hline HR & $213.1 \pm 6.6$ & $213.8 \pm 7.1$ & $212.1 \pm 6.9$ & $206.1 \pm 6.9$ & $188.5 \pm 7.4$ & $175.3 \pm 7.2$ & $169.7 \pm 8$ \\
\hline \multicolumn{8}{|l|}{ Sildenafil } \\
\hline MAP & $84.8 \pm 3.7$ & $55.9 \pm 2.5^{*}$ & $74 \pm 3.7 \dagger$ & $70.2 \pm 4 \ddagger$ & $71.5 \pm 3.2$ & $69.2 \pm 2.8$ & $69.1 \pm 2.8 \ddagger$ \\
\hline HR & $218.3 \pm 6.6$ & $236.1 \pm 4.6^{*}$ & $211.8 \pm 3.8 \dagger$ & $202.2 \pm 5$ & $180.2 \pm 6.9$ & $174.1 \pm 7.2$ & $167.8 \pm 7.1$ \\
\hline
\end{tabular}

Values expressed as means \pm SEM. $n=12-20$ per group. $* p<0.05 v s$ controls; $\dagger p>0.05 v s$ controls; $\neq p>0.05 v s$ controls but $<0.05 v s$ baseline; $\$ p<$ 0.05 vs baseline. 
served. This drop in MAP persisted through $3 \mathrm{~h}$ of reperfusion, which represented a $19 \%$ and $18 \%$ decrease for the sildenafil and the control groups, respectively, compared with baseline values $(p<0.05)$.

\section{TEE}

Both the control and sildenafil-treated groups had comparable LVCO and aortic VTI at baseline. The controls had a decline in LVCO and aortic VTI immediately after the 30-min period of ischemia (28\% and $27 \%$ lower than baseline values, respectively, $p<0.05$ ), whereas the LVCO and aortic VTI increased in the sildenafil group after ischemia (43\% and $45 \%$ higher than baseline values, respectively, $n=6$ per group, $p<$ 0.05). Both groups, however, had significant decline in LVCO after $3 \mathrm{~h}$ of reperfusion (54\% of baseline in the sildenafil group, $p<0.05$, and $62 \%$ of baseline in the control group, $p<0.05$ ), and were not statistically significantly different from each other ( $n=4-6$ per group). Both groups demonstrated a decrease in aortic VTI after $3 \mathrm{~h}$ of reperfusion. However, this decline was only statistically significant in the control group compared with baseline values. Changes in LVCO and aortic VTI are shown in Figure 3. None of the rabbits had aortic stenosis or developed aortic regurgitation for the duration of the study. Both the control and sildenafil groups demonstrated a comparable amount of mitral regurgitation (no more than mild) after ischemia/reperfusion, and none of the rabbits had baseline mitral regurgitation.
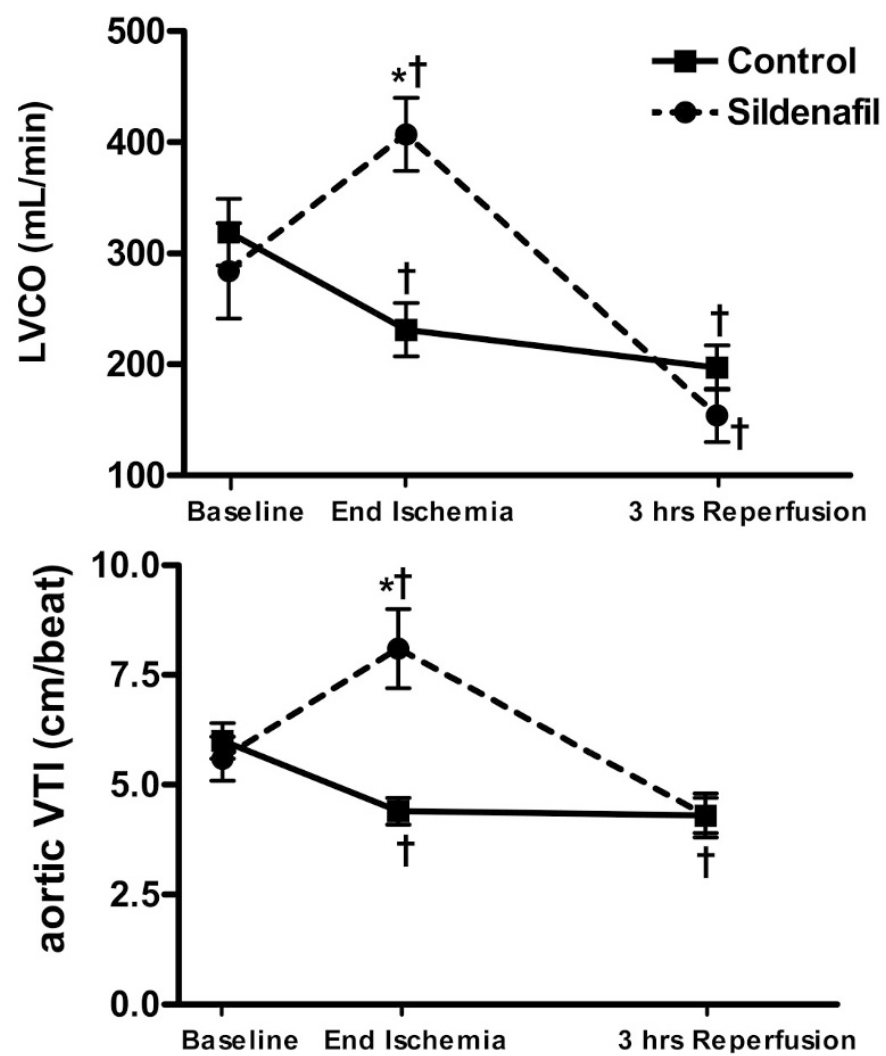

Figure 3. LVCO and aortic VTI after sildenafil infusion during ischemia/ reperfusion. $n=4-6$ per group. ${ }^{*} p<0.05, \dagger p<0.05$ compared with baseline values.

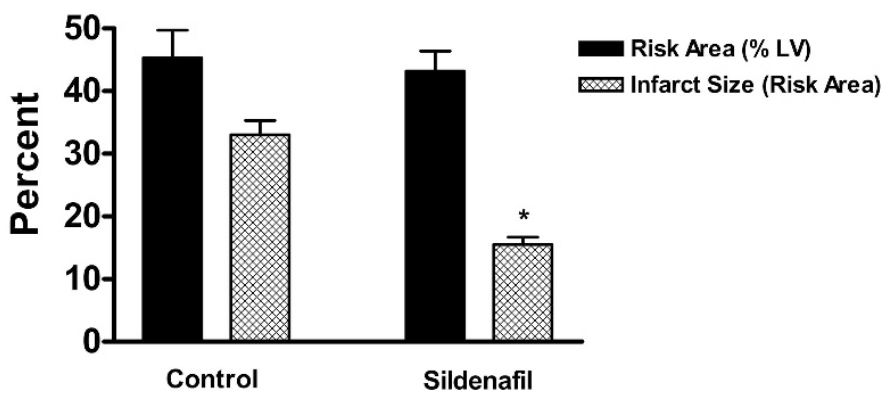

Figure 4. Bar diagram illustrating infarct size (percentage risk area) in controls $v s$ the sildenafil group compared with risk area (percentage LV). $n=$ $10-15$ per group. $* p<0.05$.

\section{INFARCT SIZE}

Figure 4 shows risk area (\% LV) and infarct size expressed as the percentage of risk area. Pretreatment with sildenafil resulted in a decrease in the infarct size from $33 \pm 2.3$ in the control group to $15.5 \pm 1.2$ in the sildenafil-treated rabbits, a $45 \%$ reduction compared with controls $(p<0.05)$. A similar trend in the changes in infarct size was observed when expressed as percentage of LV (not shown). Similarly, the differences between the risk areas were not statistically significant between the two groups. These data suggest that changes in the infarct size observed in the two groups was not related to the percentage of the area of LV occluded by our technique.

\section{DISCUSSION}

The use of sildenafil for treatment of erectile dysfunction by many patients with cardiovascular disease has resulted in a tremendous interest in the cardiovascular properties of the drug (14). Recent studies in rats have shown that PDE-5 inhibition with sildenafil attenuated the rise in pulmonary artery pressure and vascular remodeling when given before chronic exposure to hypoxia and when administered as a treatment during ongoing hypoxia-induced pulmonary hypertension (15). Clinical investigations in patients with pulmonary arterial hypertension have also shown that sildenafil therapy may be of benefit in patients receiving long-term infusion of epoprostenol $(16,17)$. Recently, we reported that administration of sildenafil-induced cardioprotection as indicated by significant reduction in infarct size when compared with controls $(11,18)$. In addition, we showed that sildenafil induced delayed cardioprotective effect in the mouse heart through up-regulation of inducible nitric oxide synthase (iNOS) and endothelial nitric oxide synthase (eNOS) (19). The hypothesis behind these studies was that the vasodilatory action of sildenafil could potentially release endogenous mediators of preconditioning such as adenosine, bradykinin, or nitric oxide. One or more of these mediators may trigger a signaling cascade leading to activation of protein kinase $\mathrm{C}(20)$ and opening of the mitoK $\mathrm{ATP}_{\mathrm{AT}}$ channel resulting in acute and delayed cardioprotective effects (11). In the present study, we have shown that sildenafil citrate also induced cardioprotection against ischemia/reperfusion injury in infant rabbits. This is evident from preservation of postischemic cardiac output and significant reduction in infarct size. 
Hemodynamics. Sildenafil citrate had a direct effect on hemodynamics by causing transient hypotension, which may have resulted in increased HR either directly or indirectly. Both groups developed the same degree of hypotension after ischemia, even though the sildenafil-treated group had increased LVCO and aortic VTI. This may reflect sildenafil's effect on the lowering of SVR. Because hypotension was again observed after the 3-h reperfusion period in both groups, and LVCO was comparable even though infarct size was reduced in the sildenafil group, it is likely that LVCO and aortic VTI may be predominantly related to SVR. We believe that sildenafil's effect on SVR, which is not directly measured by pressure and $\mathrm{HR}$, caused such a profound change and increase in cardiac output. Thus, it is also possible that the additional benefits of sildenafil may be short lived. Our results suggest that multiple mechanisms may be involved in myocardial preservation with sildenafil infusion. This may include a preconditioning-like effect as well as a direct effect on hemodynamics. The drop in MAP in both groups after the 3-h reperfusion period may reflect the fact that all rabbits were under general anesthesia for the duration of the experiment. The rabbits did receive $50 \mathrm{~mL} / \mathrm{h}$ of normal saline $(\sim 25 \mathrm{~mL} / \mathrm{kg} / \mathrm{h})$, which is the approximate equivalent of several fluid boluses as given to human infants, although infused more slowly. Because urine output was maintained throughout the experiment, we believe that renal function was preserved, and any excessive volume infused would have been accounted for by adequate urine output. We would have expected hypertension and bradycardia, or similar echocardiographic findings of increased output due to increased preload in both groups if volume had been an issue. Thus, it is unlikely that volume infusion alone led to hemodynamic deterioration in both groups after the reperfusion period.

Functional assessment. In the present study, we used 2D and Doppler echocardiography for the estimation of LVCO and aortic VTI. This may be a better marker for preserved or increased cardiac output. The use of TEE in the infant rabbit provided a long axis view of the LV and LVOT to make these calculations. This view also showed the mitral valve and a selective plane of the left ventricular myocardium. LVCO was preserved in the sildenafil-treated group mainly because of increased aortic VTI. Aortic VTI, when multiplied by crosssectional area, gives a volume measurement, or in this case left ventricular stroke volume $(13,21)$. When this is multiplied by HR, it gives LVCO $(13,21)$. HR was similar in both groups after ischemia and reperfusion, so cannot be assumed to be the major determinant. In addition, the cross-sectional area of the aortic valve annulus remained essentially unchanged as well. LVCO was elevated in the sildenafil group compared with its baseline values and compared with the control group after the ischemic period. Inasmuch as cardiac output is a function of preload, afterload, and contractility, this demonstrates the beneficial effects of sildenafil in preserving myocardial function through its effect on hemodynamics and SVR (afterload). We believe that sildenafil's effect on SVR, which is not directly measured by pressure and HR, caused such a profound change and increase in cardiac output. We cannot assume this is due to myocardial contractility alone (since this was not directly measured). It is likely that sildenafil's role in opening of
mitoK $_{\text {ATP }}$ channels contributed to less myocardial necrosis, and subsequently enhanced contractility, although this does not explain the decline in function in both groups after the 3-h reperfusion period. Perhaps to a lesser extent, sildenafil inhibited the degradation of cAMP (by its minor role in inhibiting PDE-3), and subsequently led to accumulation of ATP and improvement in contractility. In addition, it is possible that sildenafil may cause coronary vasodilation and thus lead to enhanced local and selective myocardial perfusion after an ischemic period and, again, improvement in contractility. The decline in cardiac output after $3 \mathrm{~h}$ of reperfusion in both groups suggests that functional protection with sildenafil may be short lived and, again, predominantly related to SVR. It may also be related to undefined actions of the drug itself that have yet to be determined.

Infarct size. In the present study, we observed significant decrease in the infarct size in the sildenafil-treated group compared with control rabbits. However, the degree of infarct reduction was $53 \%$ in the infant model compared with $68 \%$ in the adult rabbits (11) during acute pretreatment with sildenafil. The drug provided $75 \%$ reduction in infarct size $24 \mathrm{~h}$ after treatment in the mouse model of global ischemia and reperfusion (19). The reason for these variations is not clear although it may be related to the physiologic differences in the resistance of the infant myocardium to ischemia or stress versus the difference in response of the infant myocardium to cardiovascular drugs. Although the infant myocardium may be more tolerant of ischemia only, its response to stress, hemodynamic changes, and pharmacologic agents may be very different, thus rendering the myocardium more susceptible to injury.

Study limitations. When using Doppler echocardiography to calculate LVCO, there are several fundamental assumptions. First, that flow is laminar and organized; second, that the velocity profile is uniform across the aortic valve outlet; third, that the point of outflow used to calculate vessel cross-sectional area is circular; and fourth, that the point of measurement of cross-sectional area remains relatively constant without significant changes with hemodynamics $(13,21)$. We made every attempt to record Doppler tracings with the Doppler beam parallel with flow in the vessel and just above the aortic valve annulus, as this is the point at which maximal flow velocity should theoretically occur (13). We also measured the crosssectional area at the aortic valve annulus, as this area should be the flow-limiting point and most constant in relation to changes in hemodynamics (13). Because LVCO is preload dependent, the presence of mitral regurgitation or aortic regurgitation may potentially have an effect on cardiac output. Although we did not account for the volume of mitral regurgitation, we did assess for its presence or absence. Inasmuch as this amount was subjectively similar in both groups, we assumed that LVCO would not be substantially affected in either group. Neither group developed aortic regurgitation. Our study is also limited to a single 2D image of the long axis of the LV. This view is not able to assess all segments of the left ventricular myocardium to quantitate regional wall motion abnormalities. Although we were able to subjectively determine diminished apical myocardial contractility after infarct, we limited our study to the assessment of aortic VTI and LVCO. 
Clinical implications. For the first time, we have shown that sildenafil treatment resulted in postischemic early improvement in cardiac output during ischemia/reperfusion in infant rabbits. In addition, the drug caused significant reduction in infarct size after ischemia/reperfusion. Further studies are needed to determine the effects of hypotension alone, as well as duration and timing of drug administration on sustained preservation of myocardial function during reperfusion or days later during recovery. Because less is known about the optimum method of myocardial preservation in infants compared with adults, there is impetus for studying and developing different strategies for improved surgical outcome. In addition, because postoperative management of infants with congenital heart disease is complicated by various physiologic differences and responses to ischemia, stress, and changes in hemodynamics, it is important to devise new techniques for ideal intensive care unit care. It is possible that sildenafil citrate may be clinically important in protection of the heart in the setting of cardiac surgery using cardiopulmonary bypass, circulatory arrest, or low-flow states in infants with congenital heart disease.

\section{REFERENCES}

1. Rafiee P, Shi Y, Pritchard KA Jr, Ogawa H, Eis AL, Komorowski RA, Fitzpatrick CM, Tweddell JS, Litwin SB, Mussatto K, Jaquiss RD, Baker JE 2003 Cellular redistribution of inducible Hsp70 protein in the human and rabbit heart in response to the stress of chronic hypoxia: role of protein kinases. J Biol Chem 278:43636-43644

2. Long WA, Kirklin JK 1990 Neonatal cardiopulmonary bypass. In: Lamsback WJ (ed) Fetal and Neonatal Cardiology. WB Saunders, Philadelphia, pp 736-741

3. Lewin MB, Dreyer WJ, Fisher DJ 1998 Pathophysiology of ischemic myocardial injury and methods of myocardial protection. In: Garson A Jr, Bricker JT, Fisher DJ, Neish SR (eds) The Science and Practice of Pediatric Cardiology, 2nd Ed. Williams \& Wilkins, Baltimore, pp 279-295

4. Wernovsky G, Chang AC, Wessel DL 2001 Intensive care. In: Allen HD, Gutgesell HP, Clark EB, Driscoll DJ (eds) Moss and Adams' Heart Disease in Infants, Children, and Adolescents Including the Fetus and the Young Adult, 6th Ed. Lippincott Williams \& Wilkins, Philadelphia, pp 350-381

5. Baker JE, Boerboom LE, Olinger GN 1988 Age-related changes in the ability of hypothermia and cardioplegia to protect ischemic rabbit myocardium. J Thorac Cardiovasc Surg 96:717-724
6. Murry CE, Jennings RB, Reimer KA 1986 Preconditioning with ischemia: a delay of lethal cell injury in ischemic myocardium. Circulation 74:1124-1136

7. Xi L, Tekin D, Gursoy E, Salloum F, Levasseur JE, Kukreja RC 2002 Evidence that NOS2 acts as a trigger and mediator of late preconditioning induced by acute systemic hypoxia. Am J Physiol Heart Circ Physiol 283:H5-H12

8. Xi L, Tekin D, Bhargava P, Kukreja RC 2001 Whole body hypothermia and preconditioning of the heart: basic concepts, complexity and potential mechanisms. Int J Hyperthermia 17:439-455

9. Zhao T, Xi L, Chelliah J, Levasseur JE, Kukreja RC 2000 Inducible nitric oxide synthase mediates delayed myocardial protection induced by activation of adenosine $\mathrm{A}_{1}$ receptors: evidence from gene-knockout mice. Circulation 102:902-907

10. Kositprapa C, Ockaili RA, Kukreja RC 2001 Bradykinin $B_{2}$ receptor is involved in the late phase of preconditioning in rabbit heart. J Mol Cell Cardiol 33:1355-1362

11. Ockaili R, Salloum F, Hawkins J, Kukreja RC 2002 Sildenafil (Viagra) induces powerful cardioprotective effect via opening of mitochondrial $\mathrm{K}_{\mathrm{ATP}}$ channel in rabbits. Am J Physiol Heart Circ Physiol 283:H1263-H1269

12. Kimball TR, Meyer RA 2001 Echocardiography. In: Allen HD, Gutgesell HP, Clark EB, Driscoll DJ (eds) Moss and Adams' Heart Disease in Infants, Children, and Adolescents Including the Fetus and the Young Adult, 6th Ed. Lippincott Williams \& Wilkins, Philadelphia, pp 204-233

13. Snider AR, Serwer GA 1990 Methods for obtaining quantitative information from the echocardiographic examination. In: Lampert RH, Thorp D (eds) Echocardiography in Pediatric Heart Disease. Mosby-Year Book, St. Louis, pp 78-133

14. Gillies HC, Roblin D, Jackson G 2002 Coronary and systemic hemodynamic effects of sildenafil citrate: from basic science to clinical studies in patients with cardiovascular disease. Int J Cardiol 86:131-141

15. Sebkhi A, Strange JW, Phillips SC, Wharton J, Wilkins MR 2003 Phosphodiesterase type 5 as a target for the treatment of hypoxia-induced pulmonary hypertension. Circulation 107:3230-3235

16. Wilkens H, Guth A, Konig J, Forestier N, Cremers B, Hennen B, Bohm M, Sybrecht GW 2001 Effect of inhaled iloprost plus oral sildenafil in patients with primary pulmonary hypertension. Circulation 104:1218-1222

17. Stiebellehner L, Petkov V, Vonbank K, Funk G, Schenk P, Ziesche R, Block LH 2003 Long-term treatment with oral sildenafil in addition to continuous IV epoprostenol in patients with pulmonary arterial hypertension. Chest 123:1293-1295

18. Kukreja RC, Ockaili R, Salloum F, Yin C, Hawkins J, Das A, Xi L 2004 Cardioprotection with phosphodiesterase-5 inhibition-a novel preconditioning strategy. J Mol Cell Cardiol 36:165-173

19. Salloum F, Yin C, Xi L, Kukreja RC 2003 Sildenafil induces delayed preconditioning through inducible nitric oxide synthase-dependent pathway in mouse heart. Circ Res 92:595-597

20. Das A, Ockaili R, Salloum F, Kukreja RC 2004 Protein kinase C plays an essential role in sildenafil-induced cardioprotection in rabbits. Am J Physiol Heart Circ Physiol 286:H1455-H1460

21. Snider AR, Ritter SB 2001 Doppler echocardiography. In: Allen HD, Gutgesell HP, Clark EB, Driscoll DJ (eds) Moss and Adams' Heart Disease in Infants, Children, and Adolescents Including the Fetus and the Young Adult, 6th Ed. Lippincott Williams \& Wilkins, Philadelphia, pp 234-263 